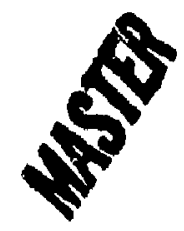

UCRL- 84079

PREPRINT

CONF - 800575--2

Weld Evaluation on Spherical Pressure Vessels Using Holographic Interferometry

Donald H. Boyd

William W. Wilcox

This paper was prepared for the Fourth International Congress on Experimentai Mechanics, Society of Experimental Hechanics, Boston, Hassachussetts, May 26-30, 1980

Nay 14,1980

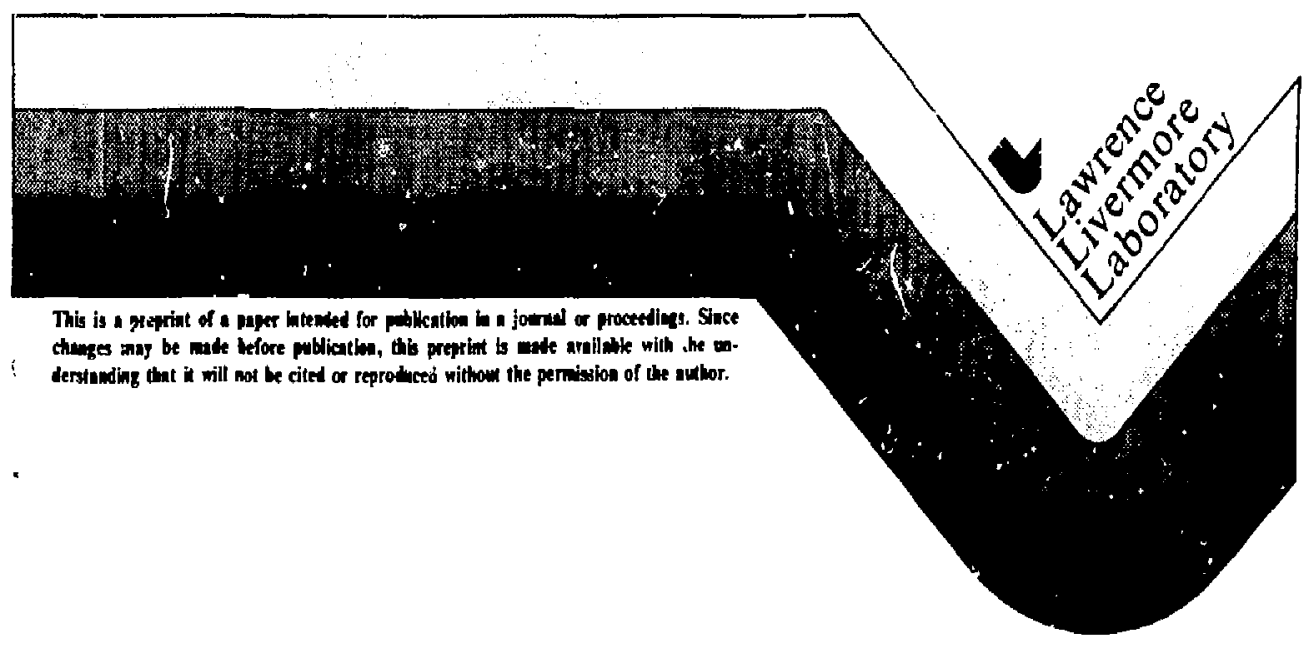




\title{
Held Evaluation on Spherical Pressure Vessels Using Holographic Interferometry
}

\author{
Donald H. Boyd \\ William W. Wilcox \\ Materials Engineering Division \\ Lawrence Liverinore Laboratory*
}

\section{Abstract}

Haist welds on spherical experimental pressure vessels have been evaluated under pressure using holographic

interferometry. A coincident viewing ard illumination opaical configuration coupled with a parabolic mirror was useo so that the entire weld region could be examined with a single hologran. Positioning the pressure vessel at the focal point of the parabolic mirror provides a relatively undistorted 360 degree view of the waist weld. Double exposure and real time holography were used to obtain displacement information on the weld region. Results are compared with radiographic and ultrasonic inspections.

Key words: holography, pressure vessels, welds, flaws, nondestructive testing

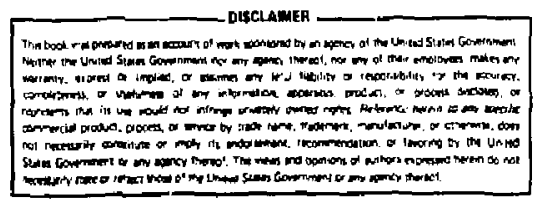

*"Work performed under the auspices of the U.S. Department of Energy by the Lawrence Livermore National Laboratoiy under contract number $W-7405-E N G-48$." 


\section{Introduction}

The nondestructive evaluation of waist welds on spherical pressure vessels is routinely mada using uitrasonic and radiographic techniques. Detailed evaluation of the ultrasonic and radiographic results is of ten difficult and can require sectioning and metallographic evaluation to verify the nondestructive testing results. A third and complementary technique which has been found to be useful for evaluating welds is double exposure holagraphic interferometry.

The noncontact, wide field of view, surface displacement measurement technique of hologiaphic interferometry has been successfully applied to the evaluation of pressure vesse?s under stress $(1,2,3)$. The method has previously been suggested as a technique for measuring weld penetration in pressure vessels (4). Recent work has shown that a qualitative evaluation of a weld on a pressure vessel can be made (5). In this work a coincident viewing and illumination optical configuration has been used. One can view approximately $180^{\circ}$ of the weld but only about the central 90 degrees gives useful information due to the part geometry. Several views are therefore normaliy required in order to ensure that full coverage of the we region is made auring a holographic inspection.

A unique optical configuration, comprising of the placement of a pressure vessel in a parabolic mirror, has been deviseo which allows for 360 degree viewing of the waist weld in a single hologram (6).

This papar describes results for two spirerical experimental pressure vessels evaluated both with and without the parabolic mirror arrangement. Results of the holographic tests are compared with ultrasonic " $C$ " scans and radiographic inspections of the waist weld. 


\section{Test Procedure}

Pressure testing of the vessels was performes in a modified high pressure cell. This cell is designed for both remote double exposure and real-time holographic testing of a variety of pressure vessels. Both the aluminum vessels described here are $76 \mathrm{~mm}$ diameter with a wall thickness of $3.8 \mathrm{~mm}$. Low-prossure testing using inert gas was employed. The weld on these vessels is of the step variety with full penetration being $3 \mathrm{~mm}$.

Two optical configurations were used to view these waist welds. The first test used a coincident viewing and illumination method (see Fig. 1). In order to cover the entire circunferential weld, the vessel was rotated for each pressure sequerice. Double exposure holography was used to record the elastic behavior of the vessel between $0.17 \mathrm{MPa}(25 \mathrm{psi})$ and $0.86 \mathrm{MPa}$ (125 psi) for each viewing direction.

The second optical configuration coliples a parabolic mirror with an almost coincident viewing and illumination arrangement. By placing the center of the vessel at the focal poirit of a parabolic mirror, the optical axis of the mirror can be aligned with the object beam and viewing direction to allow the entire waist weld to be viewed as shown in Fig. 2. Both double exposure and real-time holography were used to record the vessel displacement between 0 and $1.78 \mathrm{MPa}(200 \% \mathrm{psi})$.

\section{Results}

Two identically designed spherical pressure vessels were tested lising holographic interferometry. Figure 3 shows the double exposure interferograms for vessel A cbtained by viewing the 0 , 90,180 , and 270 degree locations. It is evident from the four 
views that the radial displacelient behavior of the vessel is nonuniform around the weld circumference. Figure 4 is a double exposure interferogram obtained using the parabolic mirror on vessel $A$. In this configuration the entire weld is viewed simultaneausiy. The fringe density and the sharpness of the pointed fringe pattern at the weid for the parabolic mirror view both indicate nonuniform radial displacement around the weld,

Figures 5 which contains the $0,90,180$ and 270 degree views for vessel $B$, show that there is much less variation in the radial displacement behavior. One draws the same conclusions from Fig. 6 the parabolic mirror view of vessel $B$.

Comparing the results from the parabolic mirror test with the coincident viewing and illumination results shows that the same qualitative information is available using either technique. The advantage of the parabolic mirror is that a single view and pressurization provides the necessary information for evaluating the waist weld.

Real-time holography was also used to record the displacement of the two vessels in the parabolic mirror optical configuration. Figures 7 and 8 show successive photographs of the interference pattern during the pressurization of vessels $A$ and $B$, respectively.

Radiographic and ultrasonic evaluations were also made on these two vesseis. Radiography on vessel A showed incomplete penetration in one area near 0 degrees, and a distorted inner step resulting in a mismatch of the two hemispheres. The ultrasonic "C" scan of vessel A shown in Fig. $g$ indicates an unfused root from $300^{\circ}$ through $45^{\circ}$. In vessel $B$ radiography revealed incomplete penetration throughout the weld length. The ultrasonic "C" $\$$ Can for vessel B shown in Fig. 10 
indicaies an unfused root for the entire weld with the worst area located from $110^{\circ}$ to $180^{\circ}$. A white area on the C-scans indicates a "good" area in the weld.

There is good correlation between the holographic and ultrasonic results for the lack of fusion regions of both vessels. Comparing the ultrasonic "C" scan results with the parabolic mirror holographic interferograms a correlation is seen between the lack of fusion and the fringe density and the sharpness of the pointed fringe in the area of the weld the lack of fusion region for vessel $A$ is located near 0 degrees. figure 3 a shows the resulting displacement caused by the unfused weld. A bending moment is present causing the vessel to displace mare on either side of the weld line. The parabolic mirror view for vessel A (Fig. 4) shows a higher fringe density (number of fringes per unit length) around 0 degrees. Vessel 8 has unfused root arjund the entire weld; this is easily visible with either hoiographic technique.

The results of the real-time holography also correlate with the uirasonic inspection. The worst area detected by the ultrasonic " $C$ " scan, the $0^{\circ}$ region of vessel $A$ and the $145^{\circ}$ region of vessel $B$, are the first areas where bending of the interference fringes is observed (see figs. 7 and 8 ).

\section{Conclusion}

A qualitative evaluation of the welds on two spherical experimental pressure vessels has been made. The nondestructive testing techniques of radiography, ultrasorics and holographic interferametry were found to be complementary in that they give indications of the same weld condition. The type of weld flaw can only be established after metallographic sectioning. The two vessels described in this report will be sectioned in order to determine if the flaw type can be correlated with the detailed features of the holographic fringe putiern. 
Quantitative evaluation of the holographic interferograms is another area being investigated. Computer raytracing techniques are being used to calculate an interferogram for comparison with real ones. This analys is of the parabolic mirror technique is expected to produce a reliable nondestructive evaluation method for circular waist weld evaluations.

\section{Acknowledgments}

We wculd like to thank Tony Schwarber and Ellen Placas for providing us with the radiographic and ultrasonic testing results.

\section{PIOTICE}

This teport was prepared as an account of work sponsored by the United States Government. Neither the United States nor the United States Department of Energy, nor any of their employees, nor any of their contractors, subcontractors, or theis employecs, makes any warranty, express or implicd, or assumes any legal liabijity or responsibility for the accuracy, completeness or usefulness of any information, appar itus, product or process disclosed, or teptesents that its use would not infringe privatelyowned rights.

Reference to a company or praduct name does not imply approval or recommendation of the product by the University of Califomia or the U.S. Department of Energy to the exclusion of others tha' may be suitable. 


\section{References}

1. Hansche, B. C. and C. G. Murphy, "Strain Measurements by Holometry", liternational Conference of Instrument Society of America, Chicago, I11., October 1971.

2. Boyd, D. M. and B. W. Maxfield, "Holographic Nondestructive Evaluation of Spherical Kevlar/Epoxy Pressure Vessels", 29th Meeting Mechanical Failures Prevention Group, NBS, Gaithersburg, Maryland, May 23-25, 1979. (UCRL-84280)

3. Boyd, D. M. "Holographic and Acoustic Emission Evaluation of Pressure Vessels". ASME Centennial PVP Conference, San Francisco, California, August 12-15, 1980. (UCRL-84046)

4. Oahike, L. W., W. Jorgenson, H. Saxton, and A. Willis, "The Performance and inspection of Flawed Pressure vessels", Sandia Livermore Laboratory Rept. SAND 76-8E54.

5. Boyd, D. M., "Holographic Inteferometry and Nondestructive Testing", Energy and Technology Review, Lawrence Livermore National Laboratory, January 1980.

6. Invention Case Ho. IL-6751, Lawrence Livermore Hational Laboratory, March 17, 1980. 


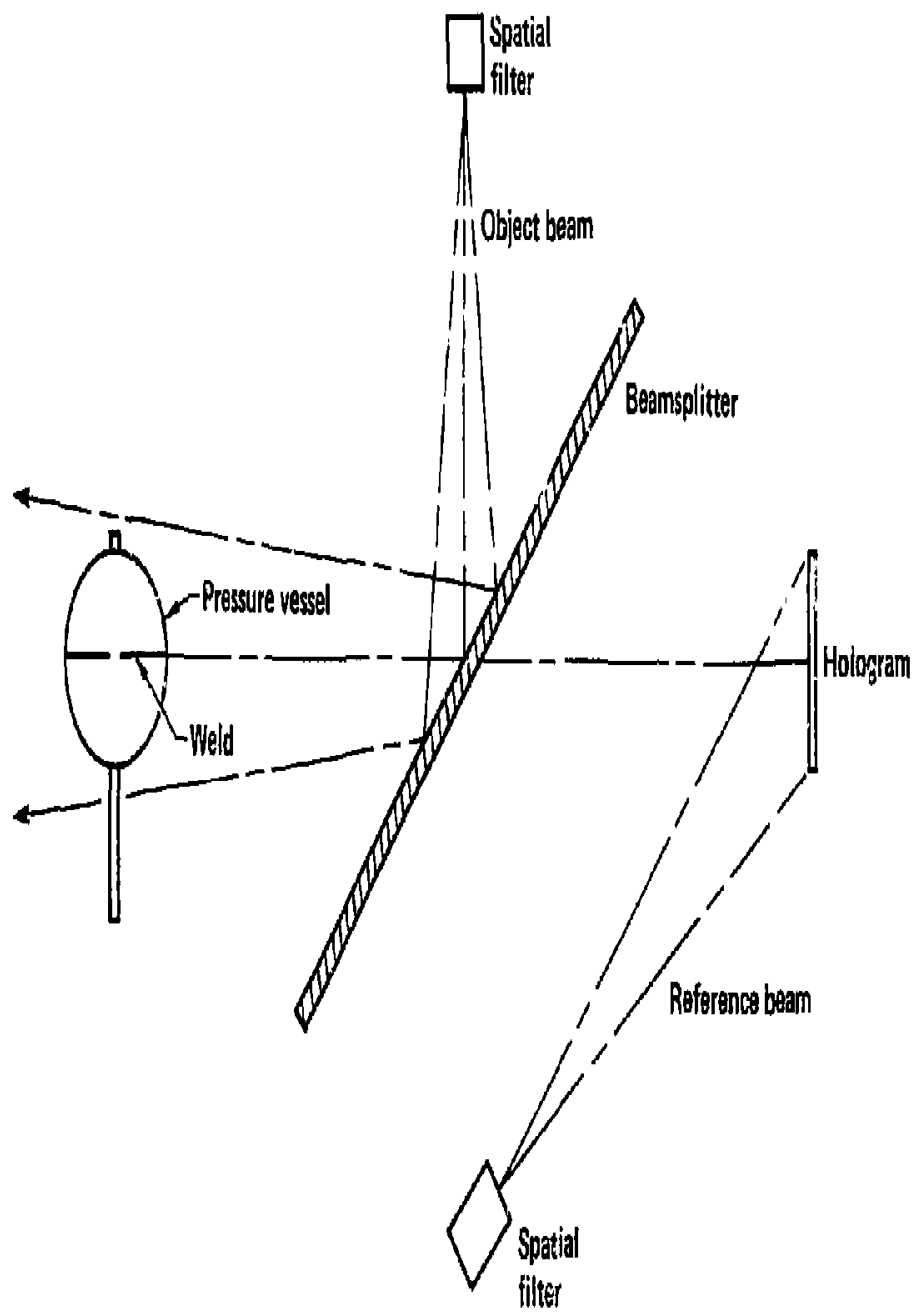

Fig. 1. Coincident viewing and illumination optical configuration ior holographic interfforogians of the pressureve vessels. 


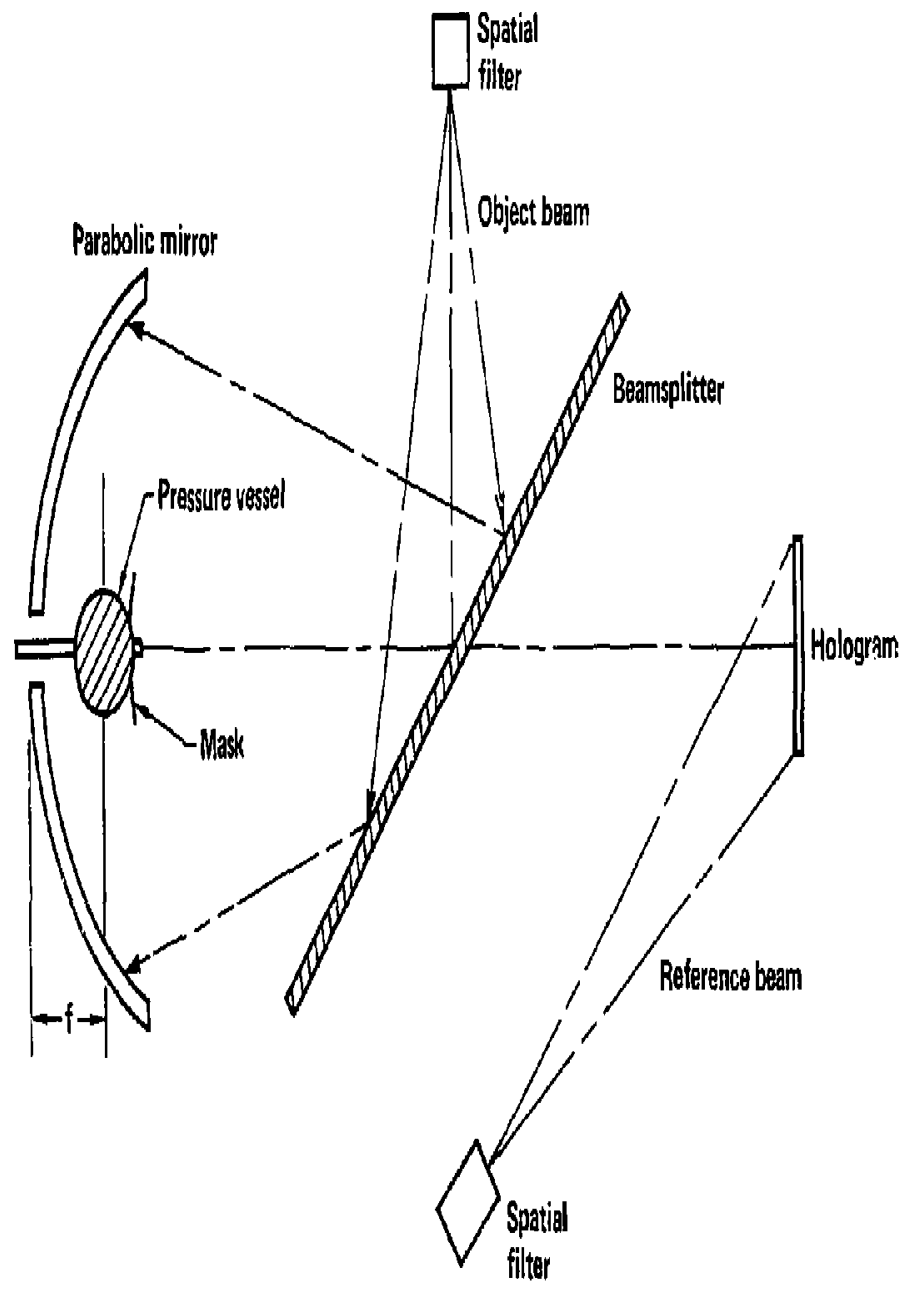

Fig. 2. Holographic optical configuration using a parabolic nirror to view 360 degres of the waiks weld. 

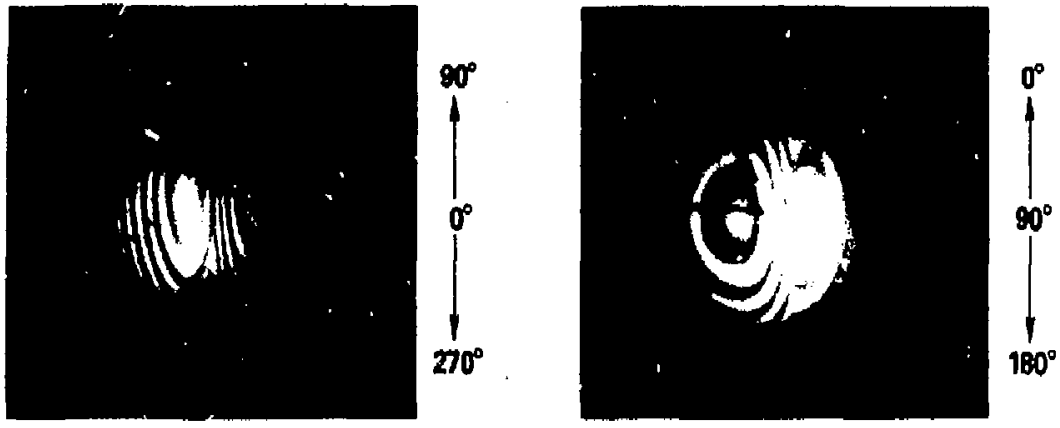

a) Odegres position

b) 90 degres pasition

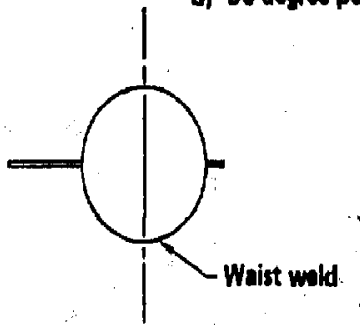

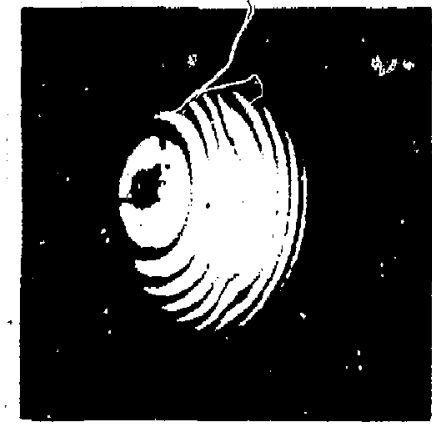

c) 100 decrea pocition

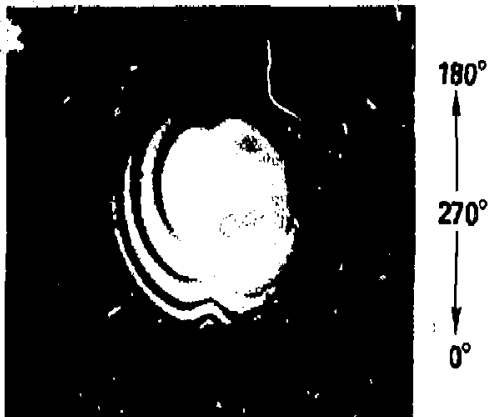

d) 270 degrm poittion

Fin 3. Colincident viawing and illeumination douste expowura holograms of vessel A for $0,90,160$, and 270 deres positions on the waist wold. (Pressure differential

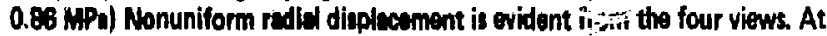
the 0 degres location lack of fusion results in a bending moment causing a non. uniform dizplacoment seross the wald. 


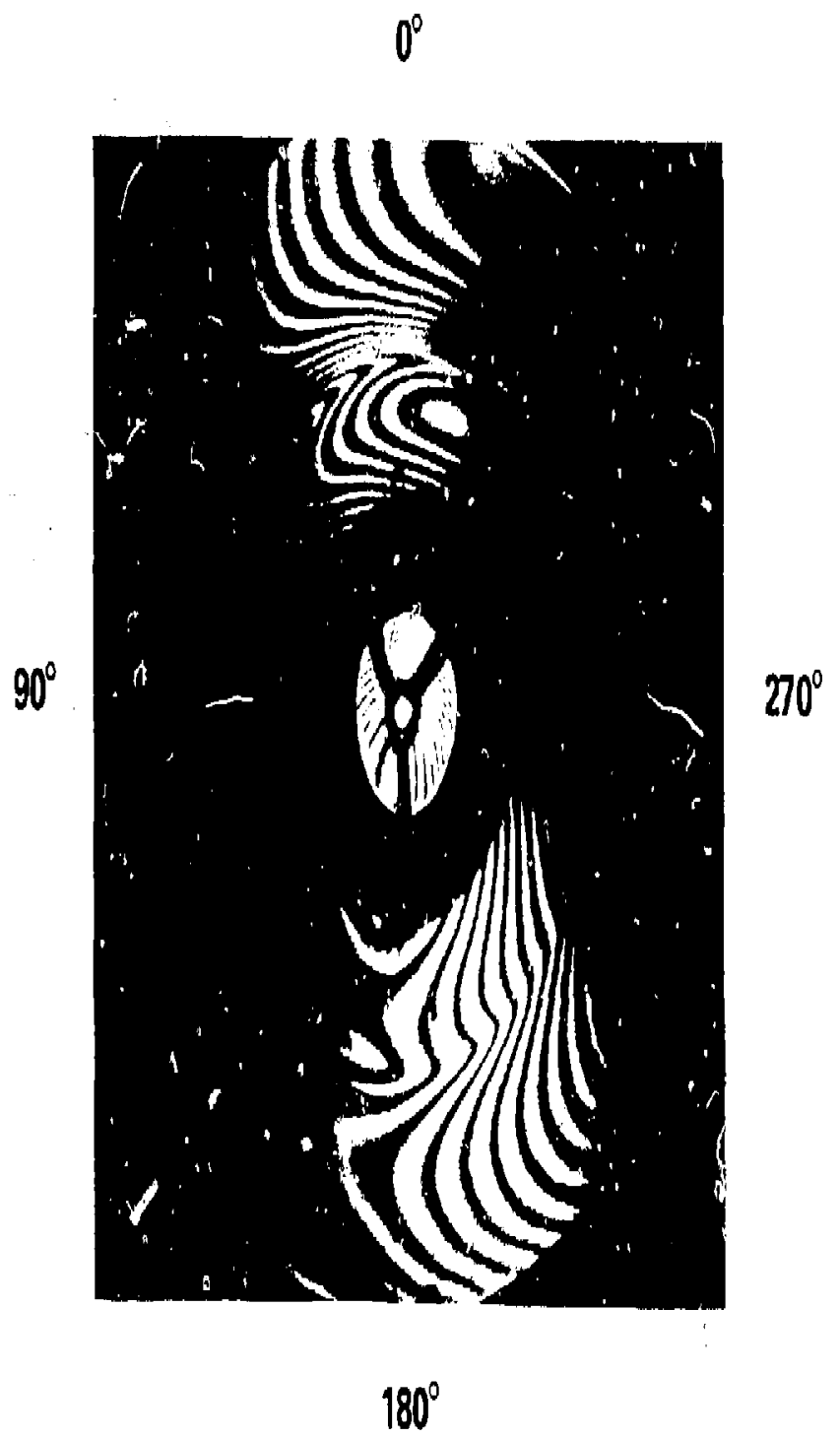

Fig, 4. Parabolic mirror double exposure hologram, (Pressure differentiti-1.78 MPa) for vesial A. The fringe density and sharpness of the pointed fringe pattern at the wedd indicaten norinifiorm radial displacemenc. The highest fringe density at 0 degrees corresponds with results from the coincident viewing and illumination hologgam shown in Fig. 3a, (ares of greatest hack of fusion). 

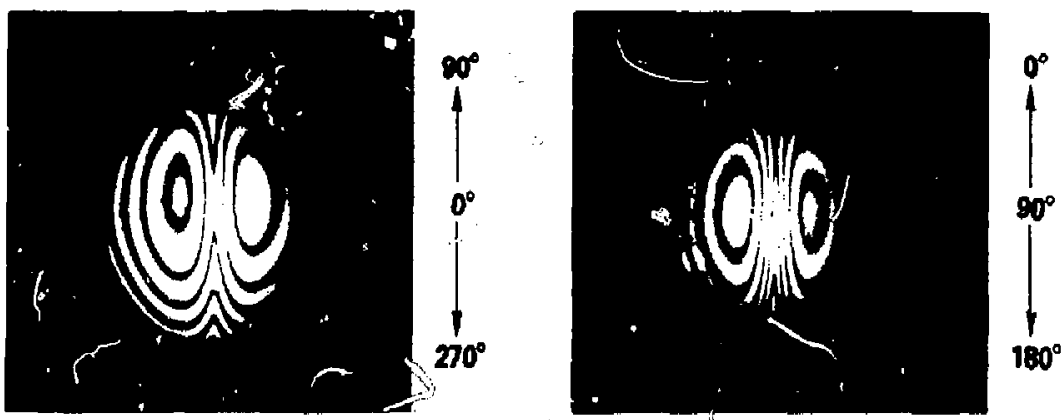

a) 0 distros position

b) 90 deqrea pexition

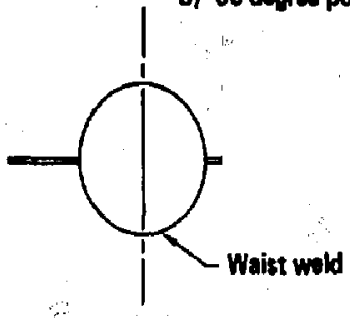

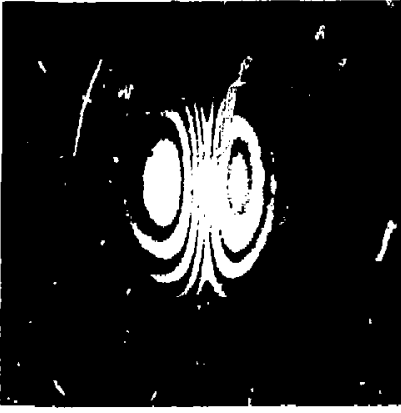

c) 180 depres position

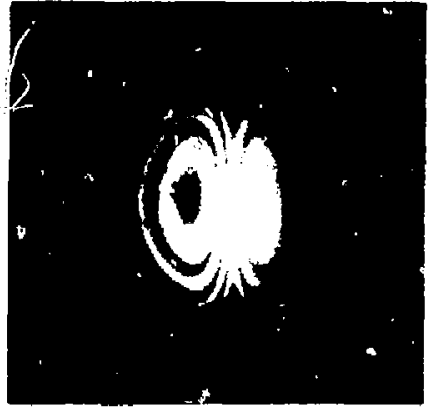

$180^{\circ}$

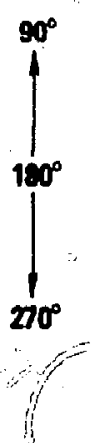

d) $\mathbf{2 7 0}$ degres podition

Fig. 5. Coincident viewing and iflumination double exposure holowems of vensel $B$ for $0,90,180$, and 270 depren positions on the waist weld. (Pressure differential $0.86 \mathrm{MPai}$ Thes hologrems show inuih less variation in the fringe pettern surrounding the weld area indicating leck of fusion around the entire waist. 


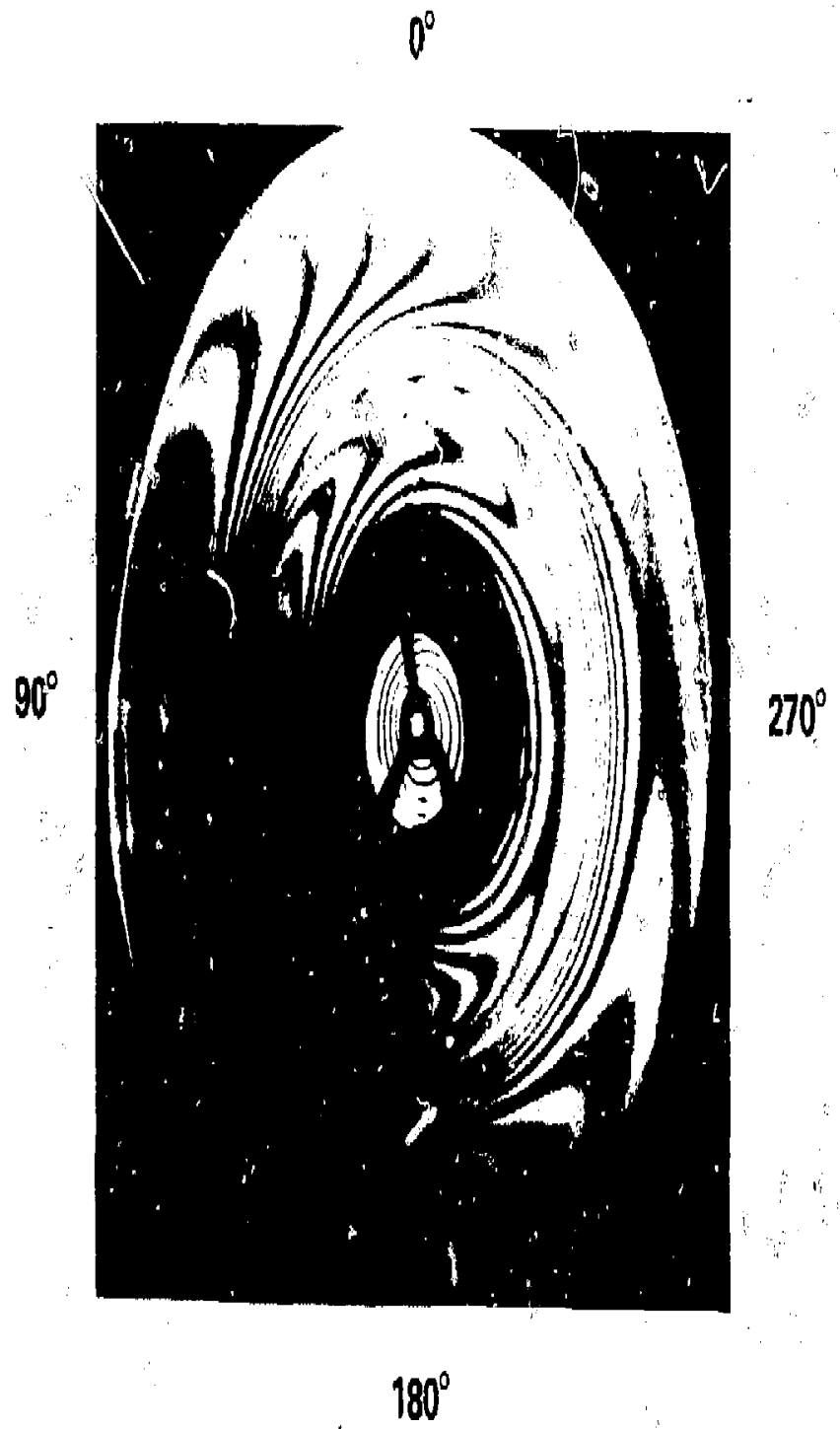

Fig. 6. Parabolic mirror double exposure hologram, (pressure differential-1.78 MPa) for vessel $B$. This shows uniform fringe density around the weld and corresponds with the ringe intormation in the holograms shown in Fig. 5. The highest tringe dentity, located from 90 to 180 degrees, indicates the area of leas fusion. 

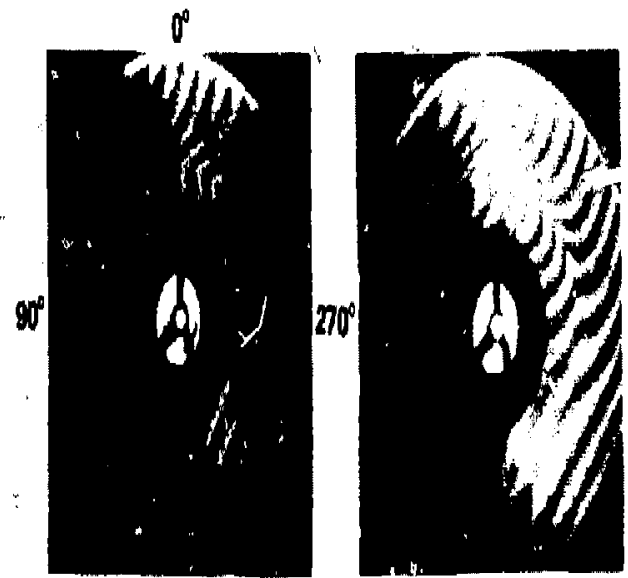

. 109

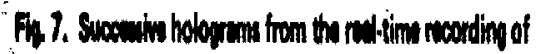

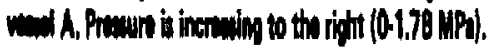

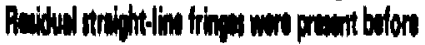

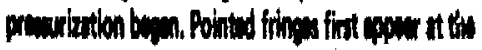
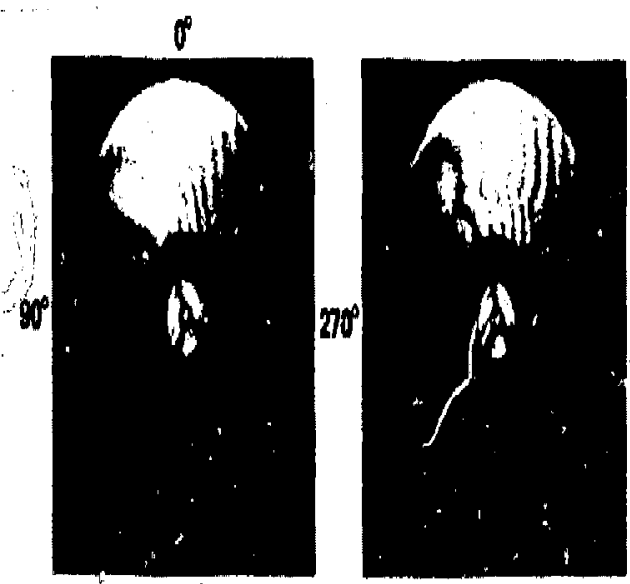

$1 N^{\prime}$

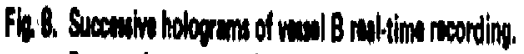
Proun increas to the right $(0-1,78 \mathrm{MP}$ ) The

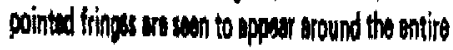
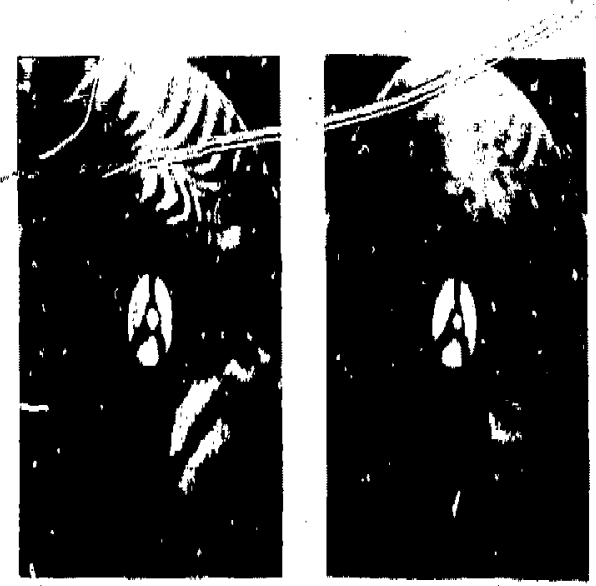

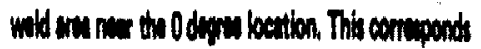

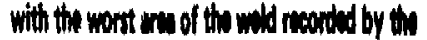
ultronic "C" con hom in Fing.
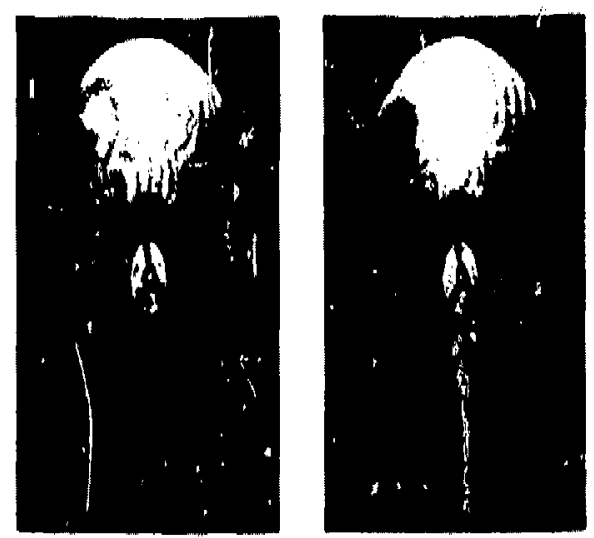

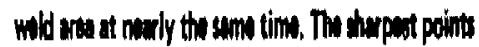
aro son a $116^{\circ}$ which cormuponds with the worn an recorded by the ultreanic "C" sen shown in Fin, 10. 


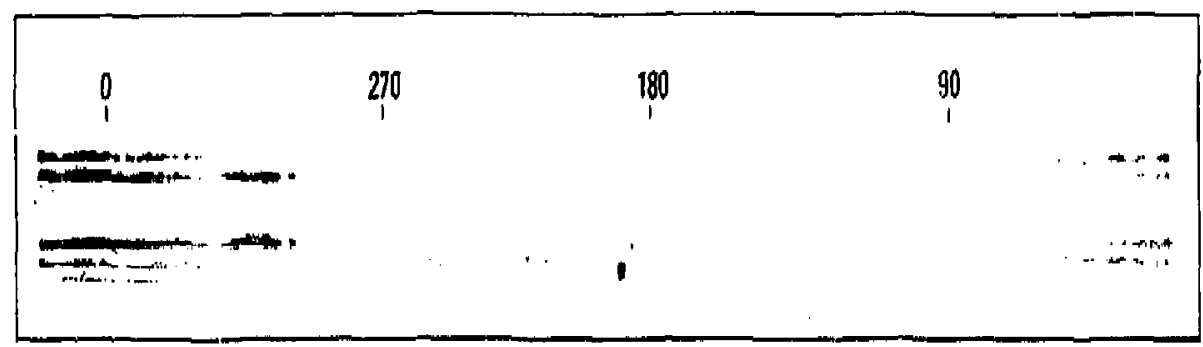

Fig. 9. Ultrasonic " $C$ " stan of weld region of the ultrasonic trensyluce? sos that a miror "essed A. A dark region indicates a flaw in the weld. Two passes are made with imsage is seen in the scan. The worst ared extends from 300 to 45 degrees.

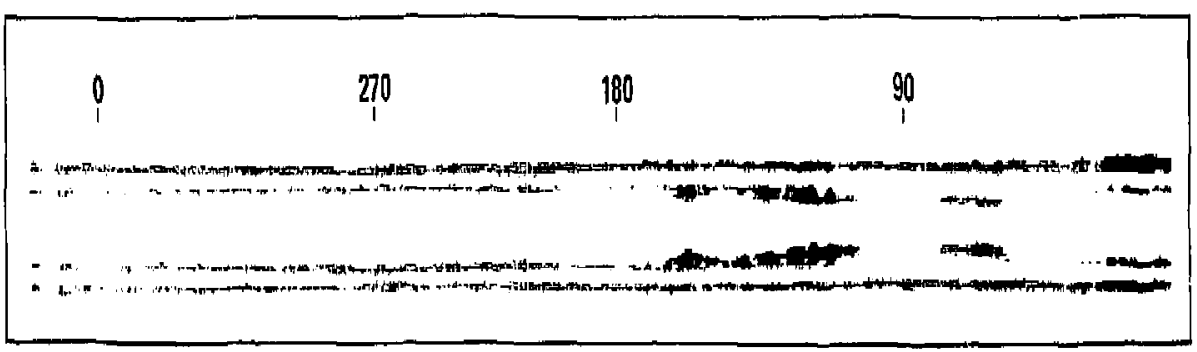

Fig. 10. Ultrasonic "C" scan of weld region of The worst area extends from 110 to 180 degrees, vessel $B$, The extent of the dark reag indicates the entire weld is "bad". 